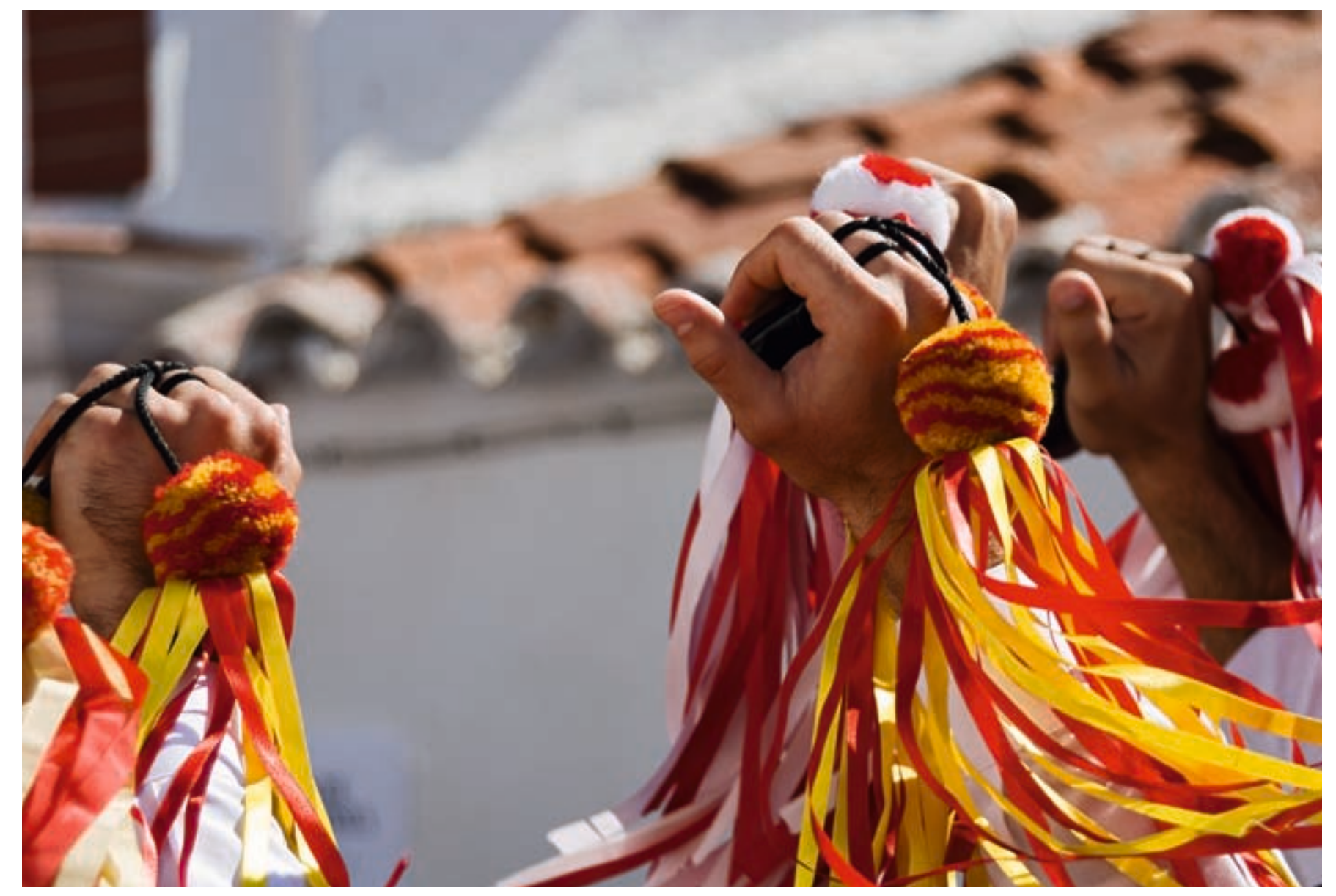

Detalle cascabeleros de Alosno. Foło: Aniceto Delgado Méndez, IAPH 


\section{La frontera como patrimonio: intercambios en la comarca del Andévalo}

Aniceto Delgado Méndez, Centro de Documentación del IAPH
Situado al oeste de la provincia de Huelva, y ejerciendo de frontera con la vecina Portugal, se encuentra una de las comarcas más desconocidas de Andalucia, el Andévalo. La ubicación y caracterización de este territorio ha influido en gran medida en el desarrollo y devenir de un lugar que se encuentra a medio camino entre la Sierra de Aracena y Picos de Aroche, y la costa, principales referentes de la provincia onubense.

Junto a las actividades ganaderas, y en menor media las agrícolas, el Andévalo ha sabido responder a las dificultades y en los últimos años un sinfín de nuevas respuestas intentan evocar un pasado que mira al futuro. El sector cinegético, la elaboración de productos derivados del cerdo y el incipiente turismo rural, todo ello acompañado del aprovechamiento de otros recursos naturales, forestales y silvícolas, que tienen en la dehesa el principal aporte, se convierten en la base socioeconómica sobre la que se cimienta su desarrollo.

En esa reinterpretación del pasado, tampoco olvida esta comarca su historia minera y prueba de ello es la recuperación de trayectos por donde transitaba el ferrocarril cargado de mineral, actual Vía Verde, en la localidad de El Granado, el museo minero de Tharsis, o los inmuebles de la Zarza-El Perrunal que nos siguen trasladando a otros momentos en los que la actividad minera se convirtió en elemento esencial del devenir de sus pobladores.

Además de la Faja Píritica del Suroeste de la Península Ibérica, rica en yacimientos de pirita y mineralizaciones de manganeso, encontramos otro elemento geográfico que influye en la caracterización del Andévalo, nos referimos al río Guadiana, corriente de agua que establece la frontera de parte de esta comarca con el país vecino y que además fue el medio a través del cual se transportaba el mineral extraído en esta zona onubense. Como ejemplo del uso del río podemos destacar el embarcadero de mineral situado en el término de El Granado y conocido como Puerto de la Laja.

Estas actividades y otras han ido conformando procesos históricos y contextos que han ido modelando un territorio donde la estrategia principal ha ido encaminada a suplir el aislamiento de esta comarca respecto de otros territorios cercanos.
Debido a este distanciamiento de los núcleos principales, adquirió un enorme protagonismo la arriería como estrategia, un tema escasamente valorado y que sin duda alguna representa un valor indiscutible en la concepción y evolución de esta comarca.

Este ir y venir provocó entre otros la venta de productos de consumo tales como el aguardiente, elaborado en el Andévalo y transportado a otros lugares de Portugal y Andalucía. Alosno, Puebla de Guzmán, Valverde del Camino, Villanueva de los Castillejos y Zalamea la Real se convirtieron en poblaciones donde la producción y consumo del aguardiente representó una gran parte de la actividad industrial.

Pero junto a diferentes productos de consumo, también se produjeron intercambios y difusión de aspectos de carácter inmaterial en forma de músicas, cantes y coplas que tienen en el fandango la expresión más significativa.

El patrimonio inmaterial del Andévalo se convierte en uno de los referentes principales de una comarca que se representa e identifica a través de diferentes romerías como la de San Benito en el Cerro de Andévalo, la de la Virgen de la Peña en Puebla de Guzmán, Piedras Albas en el Almendro y Villanueva de los Castillejos, o la de la Virgen de Coronada en Calañas. En algunas de estas romerías y otros momentos festivos, como las celebraciones en honor a San Juan o San Antonio en Alosno, San Bartolomé en San Bartolomé de la Torre, o San Sebastián en Villanueva de las Cruces, nos encontramos con expresiones tan interesantes como las danzas, prácticamente desaparecidas hasta hace unos años, y revitalizadas en el presente.

En resumen, el Andévalo, a pesar de las dificultades, continúa modelando espacios y definiendo contextos donde el patrimonio cultural adquiere un papel protagonista, y sin el cual sería imposible comprender esta comarca onubense. Las danzas rituales, romerias, fandangos, molinos de viento y otros ejemplos nos hablan de un territorio donde la frontera aparece no como un sinónimo de separación sino como un lugar cuya riqueza se cimienta en el intercambio de experiencias y formas de vida. 

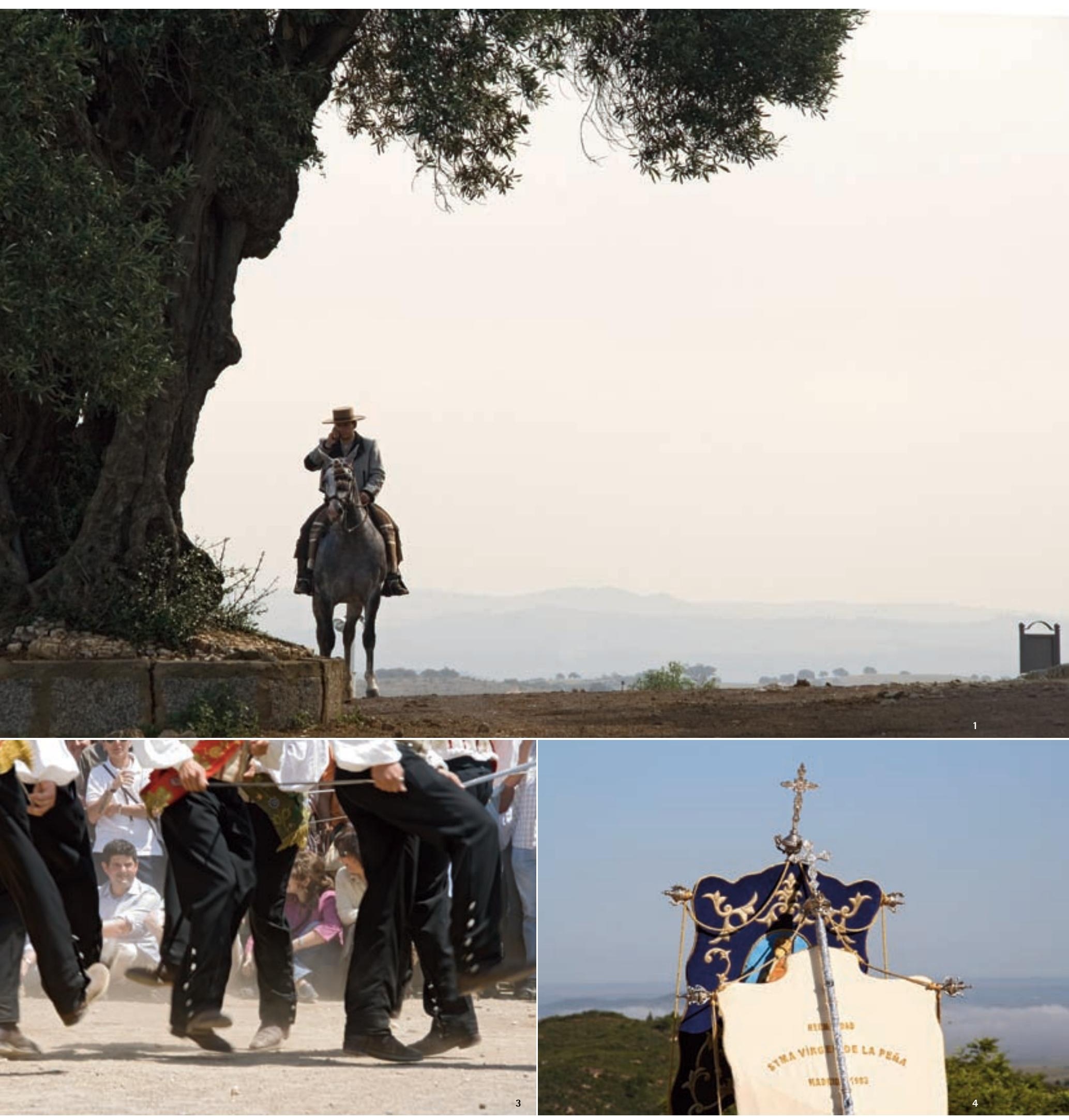

1. Romería de San Benito (Cerro de Andévalo). Foto: Aniceto Delgado Méndez, IAPH

3. Detalle danzantes en Cerro de Andévalo. Foto: Aniceto Delgado Méndez, IAPH

4. Estandarte Hermandades filiales de la Romería Virgen de la Peña (Puebla de

Guzmán). Foło: Aniceto Delgado Méndez, IAPH 

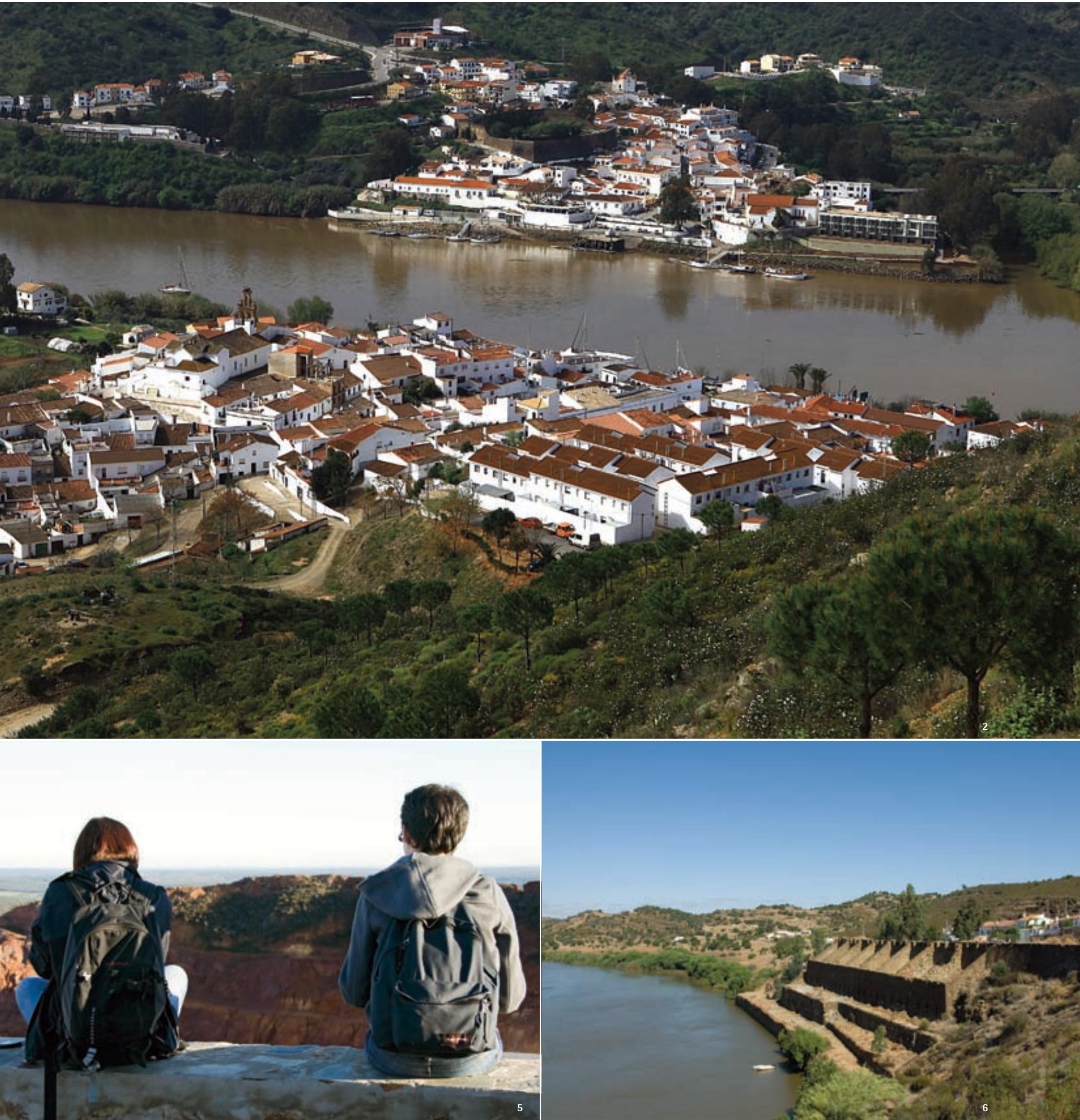

2. Sanlúcar de Guadiana localizada en la frontera con Portugal, a la margen izquierda del río Guadiana. Foto: Miguel Ángel Blanco de la Rubia

5. Minas de Tharsis en pleno corazón de la comarca del Andévalo, lindando con

los términos de Alonso al sur, Puebla de Guzmán al oeste, Villanueva de las Cruces al noreste y Cabezas Rubias al norte. Foto: Aniceto Delgado Méndez, IAPH

6. Puerto de La Laja, último punto navegable del Guadiana, en el que se encuentra un muelle de mineral, construido durante el siglo pasado y que servía para sacar piritas y otros minerales de la Cuenca Minera onubense.

Foto: Juan Carlos Cazalla, IAPH 


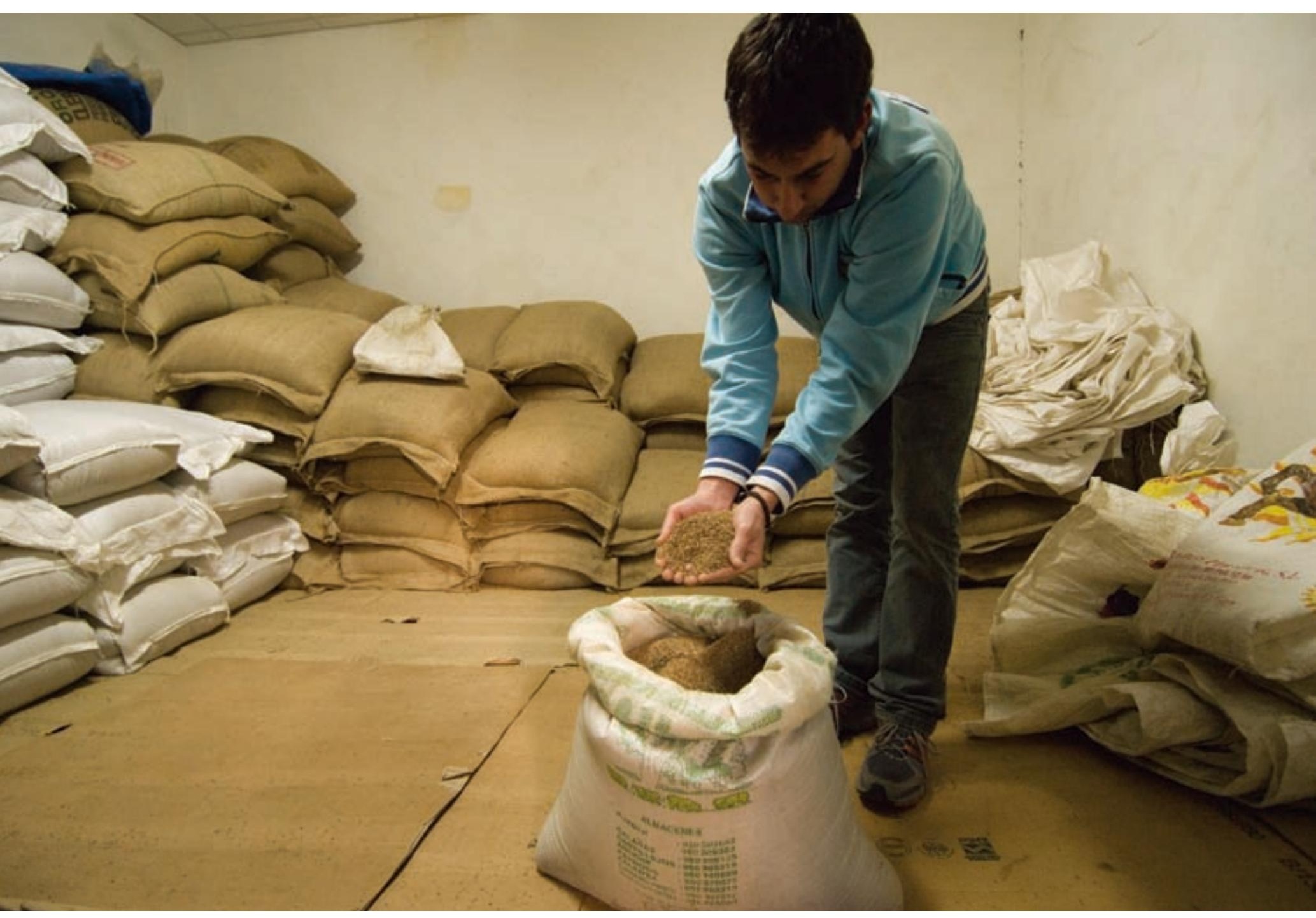

Fábrica de Anisados Arenas. Almacén de matalahúga (Zalamea la Real). Foło: Juan Carlos Cazalla, IAPH 